\title{
Construyendo el Estado: La Guardia Nacional y los entramados locales de poder en las provincias del Cauca, 1820-1850*
}

Recibido: 31/08/2020 | Revisado: 09/12/2020 | Aceptado: 22/12/2020

DOI: 10.17230/co-herencia.18.34.10

\section{Luis Ervin Prado-Arellano**}

leprado@unicauca.edu.co

\begin{abstract}
Resumen La institucionalización de las Guardias Nacionales en América Latina durante el siglo XIX formó parte de aquellas políticas republicanas tendientes a la construcción del monopolio de la fuerza. El presente artículo indaga este proceso en las denominadas provincias del Cauca, en el actual suroccidente colombiano. Su estudio es un pretexto para observar cómo la norma o la ley se vuelven realidad siempre sujetas a diversas contingencias, en las cuales la sociedad, en donde el Estado pretende fundar un orden, impacta y modela el desenvolvimiento de todas las instituciones estatales. En este sentido, se muestra cómo el proceso de conformación de las milicias en la región estuvo determinado por diversos factores y cómo, en su funcionamiento, los entramados locales de poder jugaron un papel definitivo.
\end{abstract}

\section{Palabras claves:}

Estado, Institución, instituir, instituyente, Guardia Nacional.

\section{Building the State: The National Guard and Local Power Structures in the Cauca Provinces, 1820-1850}

\footnotetext{
Abstract The institutionalization of the National Guards in Latin America during the 19th century was part of republican policies aimed at building a monopoly of force. This article studies this process in the "provinces" of Cauca, in what is now southwestern Colombia. This study aims to observe how the norm or the law always becomes reality subject to various contingencies, in which the society, where the State tries to found an order, impacts and models the development of all state
}

* Este artículo hace parte del proyecto de investigación titulado Memorias, Diarios y Guerras Civiles en el siglo XIX (ID: 4994), apoyado por la Vicerrectoría de Investigaciones de la Universidad del Cauca, y también es parte del trabajo de investigación titulado La organización de los ejércitos republicanos en la Nueva Granada: provincias del Cauca (18301855), presentado como tesis doctoral al Doctorado en Historia Latinoamericana de la Universidad Andina Simón Bolívar (Ecuador). 
institutions. In this sense, it shows how the process of formation of militias in the region was determined by various factors and how local power structures played a definitive role in their functioning.

\section{Keywords:}

State, institution, institute, instituting, National Guard.
** Doctor en Historia Latinoamericana. Profesor titular de la Universidad del Cauca, Colombia. ORCID: 0000-0002$1427-1640$

Los estudios históricos de las últimas tres décadas en torno a la construcción de los Estados latinoamericanos renovaron la forma de entender aquellas unidades políticas que, hasta ese momento, eran explicadas por medio de las visiones marxista, desarrollista y la de la teoría de la dependencia. Tales enfoques empobrecieron la comprensión de nuestras comunidades políticas, estableciendo una serie de clichés que se volvieron canónicos en la academia (Galante, 2006, p. 420; Sandoval, 2010, pp. 10-12). Entre estas miradas sobresalían las ideas de Estados fallidos, represivos, aparatos de dominación, entre otras, acompañadas de interpretaciones que anatemizaban el sistema electoral, las luchas caudillistas y el modelo de justicia de la época.

La renovación del estudio del Estado de la mano de la denominada Nueva Historia Política, ${ }^{1}$ con sus apuestas teórico-metodológicas provenientes de la Historia Social, Cultural y de las Ideas, permitió tomar distancia de las posturas ortodoxas y teleológicas que asumían las comunidades políticas como estructuras monolíticas al servicio de una clase o consideraban que existía un derrotero único -delineado por las experiencias "exitosas" de Francia o el Reino Unido- y que todo aquel que se saliera de sus moldes constituía una anomalía (Galante, 2006).

1 El revival de la Historia política fue favorecido por los procesos de globalización y la extensión del sistema demo-liberal a inicios de la década de los 90, como lo señala Jaume Aurell; pero más vital que la consolidación de este proyecto ideológico fue la renovación epistemológica. Por ejemplo, el giro cultural y su relación con los estudios del poder dotaron a la Historia Política de una vitalidad proveniente de conceptos como los de espacio público, opinión pública, cultura política, y mitos y símbolos políticos, inaugurados por Francois Xavier Guerra, para pensar el proceso de independencia (Aurell, 2017, pp. 168-180). 
Bajo esta perspectiva, se abrieron nuevos campos de indagación que hasta hace poco eran totalmente desconocidos o no despertaban ningún interés. Uno de ellos ha sido el de las Guardias o Milicias Nacionales: compañías armadas constituidas como fuerza de reserva para el ejército permanente o de línea, a partir del enrolamiento de los vecinos de los distritos parroquiales; estos debían asistir los fines de semana a los "ejercicios doctrinales", donde eran entrenados por un cuadro de oficiales veteranos encargados de impartir la disciplina castrense (Sobrevilla, 2019, pp. 333-426; véase también Harari, 2013; Hébrard, 2002; Macías, 2001, 2016; Thomson, 1990). Pero también, bajo el ideario republicano en boga durante buena parte del siglo XIX en Latinoamérica, las Guardias se concibieron como una fuerza disponible de civiles armados para enfrentar cualquier conato de deliberación política del ejército regular que pudiese derrumbar el dosel constitucional e imponer una dictadura. En resumen, las Guardias Nacionales operaron como contrapeso del ejército permanente y como cuerpo de reserva armada de la nación, para enfrentar cualquier conmoción interna o invasión extranjera. ${ }^{2}$

La idea de armar a los vecinos descansó en el principio de la ciudadanía en armas, que postulaba la defensa de la patria como un deber para los miembros de una república, aun a costa de su vida; pero, a su vez, esta idea terminó legitimando el derecho a levantarse en armas contra un gobierno, si se consideraba que este era tiránico o que amenazaba los derechos constitucionales. Esta visión hundía sus raíces en la noción de ciudadanía cívica, asociada al ideal de las repúblicas clásicas del mundo antiguo, que alentaban la participación de sus habitantes en el ejercicio público, en pos del buen gobierno y del bien común. En resumen, era una ciudadanía que, si bien no desconocía los derechos individuales y colectivos, enfatizaba más en las obligaciones con la comunidad.

Bajo estos principios, los nuevos Estados separados del imperio español constituyeron en los distritos parroquiales compañías de

Las Guardias Nacionales nacieron de la desconfianza republicana hacia el ejército regular, asociado a la monarquía. Esta visión se enraizaba en los escritos de James Harrington, uno de los pensadores de la Revolución inglesa del siglo XVII (Morgan, 2006, pp. 164-165). 
milicias, las cuales tuvieron diversos derroteros, según las experiencias nacionales. Pero con independencia de su carácter o estilo, su proceso de organización estuvo influenciado por los entramados locales de poder, que en muchos casos intentaron instrumentalizarlas para luchas faccionales. Este factor hizo más volátil el orden político en el continente, pues, al constituir las milicias, fue necesario distribuir las armas del Estado entre los vecinos, facilitando los conatos y pronunciamientos armados (Irurozqui, 2011, 2018; Velásquez, 2018).

Teniendo en cuenta este contexto, el presente artículo indaga en el proceso de conformación de las Guardias Nacionales en las denominadas provincias del Cauca, poco después de sancionada la Constitución de marzo de 1832, analizando los factores que permitieron su organización y los incentivos que tuvieron los vecinos de las provincias para enrolarse. Se sostiene que, sin el apoyo de los notables parroquiales -hombres investidos de autoridad- difícilmente se hubiesen logrado constituir las milicias. ${ }^{3}$

Este trabajo es un pretexto para analizar los procesos de construcción del Estado en las localidades; procesos desarrollados por medio del ejercicio de crear institución, fundando un orden mediante dos acciones: instituir e instituyente. El acto de instituir se refiere a la implementación de las normas en las sociedades y el acto instituyente es aquel por el cual acontece, tiene lugar y cobra sentido materializar la norma; la interacción de estos actos permite la institucionalización. Pero en la acción estatal diversos actores intervienen, pues en el acto de implementar una institución, ya sea una escuela o un

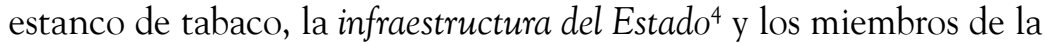

\footnotetext{
Buena parte de la información empírica aquí utilizada proviene de los Fondos documentales del Archivo Central del Cauca, en Popayán, y de otros repositorios documentales, como el de la Secretaría de Guerra y Marina, y el del general Pedro Alcántara Herrán, en el Archivo General de la Nación, utilizados para contrastar ciertas afirmaciones con otras realidades regionales del país.

4 Las instituciones estatales desarrollan un estilo propio, así sean del mismo tipo. Por ejemplo, las instituciones del presidencialismo en Ecuador y en Colombia despliegan estilos diferentes, a pesar de ser similares. Esto se debe a las bases culturales, políticas, sociales y económicas, que se engloban bajo el concepto de infraestructura del Estado y terminan siendo factores estructurales determinantes de la forma como se cristalizan ciertas organizaciones estatales. Por poner un caso, las condiciones fiscales o el nivel de conocimiento de los maestros pueden limitar la adopción de un modelo educativo: si bien este se puede aplicar, el resultado no será el mismo proyectado en el ideal. Otro ejemplo
} 
sociedad intervienen para interpretar, torcer o tensionar la norma (mediante resistencias, negociaciones, adaptaciones o acciones de hecho), de tal forma que eso que denominamos Estado y se encarna en ciertas organizaciones y funcionarios -como la alcaldía/el alcalde, la hacienda parroquial/el colector de rentas, entre otros- es producto de procesos políticos y sociales. Una vez instituidas las normas, el ejercicio de cristalizarlas (ser instituyente) es determinado por el entramado social, marcando los límites estructurales del Estado, su accionar y también sus posibilidades de mutación. De esta forma, el Estado existe a través de procesos dialécticos: funda un orden y a la vez es fundado por la sociedad, lo que permite su desenvolvimiento y cambio a lo largo del tiempo (Irurozqui, 2018, pp. 26-27; Joseph y Nuguet, 2002, pp. 31-52).

\section{Institucionalizando la Guardia Nacional en las provincias del Cauca ${ }^{5}$}

Los años comprendidos entre 1832 y 1854 señalan el proceso de institucionalización de la Guardia Nacional Auxiliar (GNA) en la Nueva Granada, por medio del acto de instituir diversas leyes y decretos orgánicos para reformar la Ley Orgánica de Milicias de 1826 (ver: Gaceta de la Nueva Granada, 1832; y la Codificación Nacional de todas las leyes de Colombia, compilada por la Sala de Negocios Generales del Consejo de Estado, 1924, t. 2 [1825 y 1826], p. 258;

es el de las reformas militares prusianas de inicios del siglo xIX: el Estado prusiano quiso adoptar el modelo del ejército napoleónico, pero no pudo implementar el sistema de reclutamiento masivo de la Nación en Armas, pues implicaba transformar las relaciones sociales de cuño medieval, aún vigentes en especial en el mundo rural de aquella nación, por lo cual debió claudicar parcialmente en copiar el modelo francés (Lynn, 1996, pp. 505-545).

5 Por provincias del Cauca hago referencia a las unidades político administrativas ubicadas al suroccidente de la Nueva Granada (Pasto, Popayán, Cauca y Buenaventura), un término, por demás genérico, con el cual se alude a la metáfora territorial que los cabildantes de Popayán utilizaron para nominar la nueva unidad territorial de 1821, llamada Departamento del Cauca. Con ello no solo buscaron mantener la preeminencia de la antigua capital de la Gobernación de Popayán, sino que fundaron una invención territorial, que posteriormente hizo curso entre los intelectuales decimonónicos, que dieron el nombre de "caucanos" a los pobladores de aquel territorio; con ello se ocultaba la diversidad social, económica, cultural y política que tenía en su interior esta vastísima área territorial. 
1925 , t. 3 [1827 y 1828], p. 415; 1926, t. 8 [1838-1840], pp. 591-603). Con estos pasos, se inició el proceso de constitución de la Guardia para sumarse a la estructura de las fuerzas armadas neogranadinas, durante buena parte de la centuria decimonónica.

Como ya se señaló, esta fuerza estaba constituida por los vecinos de los distritos parroquiales, quienes una vez alistados se reunían los fines de semana para su entrenamiento y disciplina. Pero si bien la Ley Orgánica de Milicias y las posteriores reformas que se emitieron establecieron todo lo atinente a su organización, alistamiento, entrenamiento, escalafón, asuntos de servicios y uniforme, entre otras cosas, su proceso de cristalización fue accidentado y azaroso. Los informes de los secretarios de Guerra y Marina contienen las quejas y el registro de las múltiples dificultades y obstáculos encontrados por los funcionarios encargados de la formación de las milicias.

Una de las primeras dificultades fue el alistamiento de los vecinos que formarían parte de las compañías en sus distritos. A partir de 1832, cuando se dieron las primeras directrices para su nueva organización, después de la experiencia colombiana, los funcionarios encargadas del proceso señalaron la apatía de los vecinos frente al enrolamiento, pues temían ser reclutados en el ejército permanente. La tendencia fue la de hacer varias convocatorias para que los hombres se presentasen. Así aconteció en Cartago: el 24 de noviembre de 1833, el jefe político José María Palomeque comunicó que, "felizmente", después de semanas de intentos fallidos, se había logrado organizar la compañía de milicias, expresando haber sido necesario "conducirlos presos" a los vecinos (Archivo Central del Cauca, Archivo Muerto [ACC. AM], 1833, Paquete [Paq.] 23, legajo [leg.] 15).

Una de las principales trabas que enfrentaron los encargados de organizar las milicias fue la falta de conocimiento exacto de quiénes estaban obligados por la ley a asistir al enrolamiento. Si bien la norma contemplaba que se contara con una lista de los vecinos aptos para el servicio, la generalidad fue que las alcaldías no cumplieron con aquella disposición; por lo tanto, no había medios para saber quiénes eran exactamente los hombres que debían presentarse 
al alistamiento. ${ }^{6}$ Aunque hay casos de cumplimiento de aquellas disposiciones a inicios de la década del treinta, en las parroquias de Guacarí, Cerrito y San Pedro, pertenecientes a la jurisdicción de Buga, este cumplimiento fue marginal, porque, a lo largo del periodo de estudio, no hay más referencias a este asunto (ACC. AM, 1833, Paq. 23, leg. 15; 1834, Paq. 24, leg. 25).

Además, varios vecinos se resistieron al alistamiento, aduciendo estar eximidos por su fuero: de estudiantes, funcionarios públicos, etc., ya que la Ley Orgánica Militar los eximía del servicio (ACC. AM, 1840, Paq. 31, leg. 46). Pero más complejo aún era el hecho de que la profesionalidad de una compañía de Guardia Nacional dependía de la asistencia constante de sus miembros a los "ejercicios doctrinales", para entrenarse y así obtener la disciplina necesaria para ser realmente un cuerpo armado, capaz de responder de modo adecuado cuando fuese llamado al servicio. Es decir, no bastaba la convocatoria inicial, era necesario la asistencia regular los fines de semana, para ganar experticia castrense.

En esta etapa, la inasistencia a los días de entrenamiento fue la constante de los miembros de la Guardia, un fenómeno que iba en aumento con el pasar de los meses y el cual atentaba contra el espíritu marcial, a tal punto que en una revista militar de 1835, en Popayán, se informó que en varias compañías se notaba la "falta de celo necesario en la organización y disciplina” (ACC. AM, 1835, Paq. 25, leg. 24), agregando que algunas unidades en las parroquias no contaban con las armas para el entrenamiento (ACC. AM, 1839, Paq. 29, leg. 27; 1843, Paq. 36, leg. 47; 1851, Paq. 50, leg. 50; 1851, Paq. 51, leg. 48).

Por estas razones, el 18 de octubre de 1842, el gobernador de Popayán, Francisco de Paula Torres, elaboró un texto de once puntos sobre la convocatoria, organización, entrenamiento y disciplina de la Guardia Nacional Auxiliar, que contenía las directrices para un mejor control de la asistencia, tanto de los oficiales como de los

\footnotetext{
La edad de reclutamiento en la Guardia Nacional Auxiliar primero fue entre los 16 y los 50 años, pero con las reformas a inicios de la década del cuarenta, se estableció entre los 18 y los 40 años (Sala de Negocios Generales del Consejo de Estado, 1926, t. 8 [18381840], p. 592; 1928, t. 13 [1848-1849], pp. 525-529).
} 
soldados. En el texto se determinó que los oficiales que residieran en los lugares donde estuviera la plana mayor del cuerpo se reunieran en "academia" dos veces al mes, para instruirse "en los principales rudimentos de las ordenanzas militares, táctica, servicio de armas". Además, se exigió la enseñanza de la ordenanza para todos los oficiales residentes en las parroquias distantes y, para los milicianos, la instrucción en la Ley orgánica, al menos una vez al mes, "en la parte que trata de sus obligaciones [...] manifestándoles la sagrada obligación, que tiene cada uno de ellos en particular, y todos en general de sostener y defender la constitución y las leyes de la república, mantener el orden público principalmente en los lugares de domicilio" (ACC. AM, 1843, Paq. 36, leg. 27).

En resumen, de los once puntos, seis estaban dirigidos a la instrucción, la disciplina y la promoción del espíritu del cuerpo, por medio de lo que hoy se denomina doctrina militar. Sin duda, el gobernador estaba al tanto de una de las principales dificultades que tenía la milicia en la región: su falta de regularidad en la asistencia a los ejercicios doctrinales. Sus órdenes estaban en consonancia con los esfuerzos que durante esos años el Estado central promovía para constituir unas fuerzas militares más profesionales y eficientes, después de la experiencia dejada por la pasada guerra civil, conocida como Guerra de los Supremos (Sala de Negocios Generales del Consejo de Estado, 1927, t. 9 [1841-1842], pp. 267-270).

Francisco de Paula Torres, consciente de que la Guardia Nacional era un cuerpo dependiente de la voluntad de los vecinos, sabía de la necesidad de construir un sentimiento de adhesión. Por esta razón, recomendó establecer las "academias", espacios dedicados a impartir conocimientos sobre las ordenanzas militares, para oficiales y milicianos; dar "doctrina", construir ethos castrense y, de esta manera, otorgar identidad y sentido de pertenencia a los milicianos.

Desafortunadamente, existen pocos registros que nos permitan identificar esos momentos en los cuales se impartió doctrina a los miembros de la Guardia. Pero, sin duda, fue de los años cuarenta en adelante cuando se prestó mayor atención al tema. Durante el periodo liberal, con su política de liquidar el ejército permanente y convertir la Guardia Nacional en la columna vertebral de la defensa 
nacional, el gobierno instó a que los miembros de las sociedades democráticas se alistaran en las milicias y exigió, por medio de la Ley de 29 de mayo de 1850, impartir instrucción en los principios políticos que se promovían.

De esta manera, las alocuciones públicas hechas por los comandantes y líderes liberales a las compañías de milicias formaron parte de las doctrinas impartidas a estas unidades armadas. Las nociones de libertad, igualdad, fraternidad, deberes y derechos de los ciudadanos; la lucha contra toda forma de vasallaje y la defensa del régimen liberal frente a sus enemigos estuvieron entre las ideas que se difundieron. Por ejemplo, el 22 de diciembre de 1850, el alcalde y comandante del escuadrón de Húsares del Patía, Manuel María Vargas, se dirigió a una de las compañías que comandaba, así:

Soldados de la $2^{\underline{a}}$ compañía del escuadrón de Húsares número primero, sed primeros y subordinados, de cuyo modo siempre triunfáis, y seréis útiles a la patria sosteniendo con nuestro valor los principios de la causa santa de la libertad (este sólo nombre encanta es sublime) da una mirada hacia atrás i encontrareis que vuestros antepasados desde el año 28 derramaron su sangre por contribuir a dar la libertad a los pueblos que gemían bajo el yugo de los déspotas de la Nueva Granada. [...] Sostengamos los principios del gobierno y la verdadera democracia y si es necesario fuere al campo de Marte a castigar al enemigo, no temáis revueltas que el verdadero patriota siempre tiene levantada la frente diciendo ¡Viva la república de la nueva Granada, viva el digno jefe que la preside! ¡Viva el padre de las libertades públicas, ciudadano general José María Obando y viva el antiguo patriota ciudadano general Manuel María Franco comandante de los pueblos del sur! Patía 19 de diciembre de 1850 (ACC. AM, 1850, Paq. 48, leg. 64).

Si bien pocas de estas alocuciones se conservan, esto no significa que fueran marginales. Las milicias eran constantemente adoctrinadas en los principios republicanos y en sus deberes frente a la nación. Esto, sin duda, ayudó a su cohesión, pero también había otras prácticas, más relacionadas con la liturgia política, que contribuyeron al ethos castrense; por ejemplo, la jura de la bandera, un ritual iniciático que se hacía cada vez que se organizaba una compañía o se reunía un batallón, en el cual sus miembros, presididos por su comandante, juraban lealtad al símbolo patrio (ACC. AM, 1834, Paq. 24, leg. 25). 
Los primeros ejemplos de esta práctica de juramento de fidelidad al símbolo nacional durante el periodo de estudio datan de los días 9, 16 y 19 de noviembre de 1834, en Almaguer, el Tambo y Tunía-Silvia, respectivamente (ACC. AM, 1834, Paq. 24, leg. 25). La ceremonia en cuestión estaba totalmente reglada, como lo expresó el 6 de noviembre de 1834 el gobernador de la provincia al jefe político de Palmira, Mariano Borrero, indicándole que leyera las instrucciones existentes en el decreto emitido por el Poder ejecutivo el 23 de agosto de ese año (ACC. AM, 1834, Paq. 24, leg. 25). No obstante, en la práctica se adoptó una variante no contemplada por la norma, un rito religioso de bautizo de la bandera, con un "padrino", el cual era una persona de prestigio en la localidad, quien financiaba el ágape después de concluido el acto (ACC. AM, 1834, Paq. 24, leg. 25; 1837, Paq. 37, leg. 72; 1842, Paq. 35, leg. 42; 1851, Paq. 50, leg. 50.). Ser padrino era un cargo honorífico oneroso, pero al titular le servía para reafirmar su prestigio ante la comunidad y construir lazos con los miembros de la compañía armada, como lo han identificado algunos estudios antropológicos sobre el tema (Mintz \& Wolf, 1978, pp. 1-15; Nutini y Bell, 1989).

La jura de la bandera, en todo caso, debió tener un significado especial, para que el 15 de noviembre de 1841, en la localidad de Simaña, dos miembros de la recientemente organizada Guardia Nacional de Málaga se negaran a jurar fidelidad a la bandera. Si bien el comandante consideró, como castigo, pasarlos a las armas, decidió finalmente hacer una corte marcial "por sedición e inobediencia en el acto de presentar juramento de fidelidad a la bandera". De las declaraciones de los incriminados se desprende que eran miembros recién alistados en la Guardia y que no tenían ningún conocimiento de las ordenanzas; además, uno de ellos expresó, "con cierta candidez que persuade el ánimo de los jueces de que no cometió el delito de malicia, [...], expresando que no había querido jurar, porque su padre le había aconsejado que no jurase porque se condenaba". Este hecho insinúa cómo las percepciones modelaban los comportamientos de los actores frente a ciertas liturgias castrenses (Archivo General de la Nación. Academia Colombiana de Historia. Fondo Pedro Alcántara Herrán [AGN. ACH. FPAH]. Rollo 6, leg. 10). 
La bandera, sin duda, era un símbolo de adhesión y fidelidad a un cuerpo, a tal punto que en las guerras civiles, cuando alguien cambiaba de bando, se decía que "abandonaba las banderas". Esta centralidad se debió a su presencia en diversos actos públicos, por ejemplo, en la jura a la Constitución, o como ocurrió el 4 de noviembre de 1831, en el Socorro: al recibirse la noticia de la instalación de la convención constituyente de la Nueva Granada, la comandancia y el gobernador decidieron hacer pública la nueva; de un modo solemne, se decretaron tres días de regocijos públicos y la fuerza armada se ubicó en la plaza mayor, dando vivas a la convención; entonces, "tremoló una bandera nacional con la inscripción que en copia incluyo y en la segunda en cuatro circas en los ángulos de la plaza se izaron en cada uno de ellos una banderola con moños" (Archivo General de la Nación. Secretaría de Guerra y Marina [AGN. SGM]. Tomo 160, folios 1204-1205).

La liturgia republicana, con la presencia de los símbolos patrios y los estandartes de los cuerpos armados (permanentes o milicia), estuvo presente en diversos momentos: al celebrarse la conclusión de una guerra civil, en las procesiones de la Semana Santa, al declararse la abolición de la esclavitud, entre otros (ACC. AM, 1843, Paq. 37, leg. 70; 1850, Paq. 49, leg. 76; 1852, Paq. 53, leg. 77; Bosch, 1996, pp. 47-48). Una de las mejores descripciones de estos actos es la de las celebraciones realizadas el 19 de diciembre de 1854 en Popayán, por el triunfo constitucional sobre el General Melo. Allí desfilaron los cuerpos de Guardia Nacional de los distritos parroquiales y se hizo un esfuerzo por representar a la nación:

Un carro elegantemente adornado, tirado por dos hermosos caballos blancos, y sobre él sentada la señorita Clementina Pombo, que simbolizaba a la provincia de Popayán, tras el carro y en dos filas, marchaban treinta y cuatro niñas, representando cada una, a una de las provincias de la República, cuyo nombre llevaban escrito en letras de oro, sobre una banda azul celeste (ACC. Fondo Arboleda [ACC. FA]. Signatura 336, folios 27v-28r).

Otro mecanismo que las ordenanzas de milicias contemplaron para constituir una identidad castrense fue el uniforme, que, como

$7 \quad$ Nueva era una expresión de la época que aludía a una noticia. 
lo han señalado algunos investigadores, fue vital en la construcción de un espíritu de cuerpo (McNeill, 1989, pp. 145-146). Las primeras medidas al respecto datan de la Ley Orgánica de 1826, que dejó su financiamiento en manos de los milicianos; medida poco efectiva. Por ello, en la década siguiente hubo un interés creciente por dotar a las Guardias de vestuario, al igual que a los cuerpos regulares, entregándole a los milicianos un uniforme al entrar en servicio y descontándoselo del prest o pago que se les asignaba mensualmente (ACC. AM, 1839, Paq. 29, leg. 25).

Había otros mecanismos vitales al momento de constituir la identidad de las Guardias Nacionales, entre ellos estaba la elección de los oficiales de las compañías y los escuadrones, por medio del voto, a viva voz, por parte de sus miembros. La Ley Orgánica de 1826 contempló este mecanismo, pero quedó en la potestad del Ejecutivo la aprobación de tales designaciones, como un mecanismo de control para que los mandos quedasen en personas de confianza (Sala de Negocios Generales del Consejo de Estado, 1924, t. 2 [1825 y 1826], pp. 258-260). La idea de los comicios era promover un espacio de aprendizaje democrático y de las virtudes republicanas; pero, a su vez, era una estrategia, en el sentido de que los mismos milicianos elegían a sus jefes y oficiales de entre sus vecinos, en lugar de ser impuestos "desde arriba", para fortalecer la unidad de las compañías.

La elección de los oficiales de la Guardia Nacional expresa el proceso complejo de institucionalizar el Estado, por ser un campo de lucha entre diversos actores, al intentar convertir la norma en acto. En primer lugar, el sistema de elección por votación permitió, como lo informó el jefe político de Cartago en agosto de 1833, que algunos hombres aptos para los cargos sujetos a voto, por "su eficacia, modales, valor y honradez", intrigasen para no ser elegidos y poner en los cargos a otros menos idóneos; así evitaban comprometerse, dando por resultado, según el funcionario, "la disolución de las milicias", al elegirse oficiales ineptos. De ahí la propuesta de facultar al Concejo municipal para elegir a los oficiales, por contar con el conocimiento de los habitantes de la localidad y, por ende, saber cuáles serían los adecuados para el nombramiento; de esta manera, se anularía a los egoístas, quienes "no hallan los claros para eludir la ley" (ACC. AM, 1833, Paq. 23, leg. 15). 
Otra de las dificultades fue que en la organización inicial de la Guardia Nacional en la región se buscó que cada parroquia tuviese la experiencia miliciana, formando medias compañías por distrito y desatando así un conflicto en la elección de los oficiales, pues cada parroquia quería que el capitán de la unidad fuese su vecino. Esta fue la razón por la que el jefe político de Tuluá, Juan Antonio Rebolledo, escribió una carta el 31 de agosto de 1833, señalando al gobernador que tenía dudas respecto a la elección de los oficiales y el escrutinio, pues no sabía si la encargada de sufragar por el capitán o el teniente era la media compañía de Buga o la de Tuluá, o en cuál localidad debía hacerse la votación (ACC. AM, 1833, Paq. 23, leg. 15).

En esta misma línea se inscribe el disenso al interior de la compañía constituida entre Cali y Caloto. En este caso, por el distanciamiento político existente en ese momento entre las dos localidades, debido a las posiciones asumidas frente a la dictadura del general Rafael Urdaneta (septiembre de 1830-abril de 1831). Dada esta situación, el 25 de septiembre de 1833, el jefe político de Caloto, Fernando Carvajal, concluía que "no se puede hermanar esta compañía dividida en dos partes", agregando que la elección de oficiales iba a generar inconvenientes por la rivalidad existente (ACC. AM, 1833, Paq. 23, leg. 15).

Sin embargo, las elecciones de oficiales por medio del sufragio fueron solo una breve experiencia de ciertas localidades de las provincias de Buenaventura y Cauca, en los años treinta, pues de tales territorios proceden los únicos informes de la aplicación de la norma, entre 1833 y 1834 (ACC. AM, 1833, Paq. 23, leg. 15). En adelante, hay un silencio documental, que sugiere la falta de aplicación de la norma y la elección de oficiales por otros medios. Solo durante el régimen liberal de mediados de siglo hay un revival de aquella práctica, que incluye algunos distritos de la provincia de Popayán, pero no para la Guardia Nacional Auxiliar, sino para la Guardia Nacional Local, como lo indica el informe de votaciones para jefes y oficiales elaborado por el jefe político de Almaguer, el 24 de agosto de 1852 (ACC. AM, 1852, Paq. 53, leg. 77).

Los registros archivísticos sugieren que la designación de los oficiales para la Guardia Nacional al sur del río Ovejas, es decir, en 
las provincias de Popayán y Pasto, para los años treinta y cuarenta, se hizo a partir de las ternas elaboradas por las autoridades provinciales y locales, y refrendadas por la Secretaría de Guerra. El uso de esta forma de elección, en contravía de la norma, radicaba en el hecho de que en la región los comandantes de milicias por antonomasia, desde los años veinte, habían sido jefes o militantes de partidas guerrilleras realistas, adheridos al régimen republicano a partir de 1821, gracias a una negociación con el naciente Estado, el cual les otorgó una amplia amnistía a cambio de que juraran fidelidad a la República.

Bajo esta política de negociación, varios líderes guerrilleros del Patía, San Antonio, La Sierra y el Tambo, entre otros, se plegaron a las banderas republicanas, obteniendo el reconocimiento de sus grados alcanzados en las filas realistas. De esta manera, el Estado obtuvo comandantes, y huestes curtidas en la guerra de guerrillas y veteranas en una clase de estrategia todavía necesaria para consolidar el régimen político naciente (Prado, 2012, 2013). Esta conversión de guerrilleros realistas a soldados republicanos le permitió al nuevo régimen tener a su disposición gendarmes en poblados aún reacios al sistema republicano, dispuestos a someter a las últimas guerrillas realistas, que aún pululaban entre Almaguer, La Cruz y el Tambo, hasta bien entrada la década del veinte.

Tales hombres, por su condición de notables parroquiales, terminaron ejerciendo en la primera mitad del siglo XIX los cargos de alcaldes, alguaciles, comisarios, mayordomos de fábrica, entre otros. En otras palabras, fueron los representantes del Estado en sus comunidades y, a su vez, mediadores entre el orden político nacional y local (Prado, 2012).

Es decir, la ausencia de votación para elegir a los oficiales de la Guardia Nacional en la provincia de Popayán obedeció a que las autoridades provinciales, al ser conscientes de la centralidad de los notables parroquiales -o, como los llamaba Mariano Ospina, los magnates-, optaron por nombrarlos y tramitar sus despachos ante la Secretaría de Guerra -sin mediación electoral-, para convocar, alistar y organizar las compañías de milicia en sus aldeas. Además, las autoridades dejaron a discreción de los notables el nombramiento de los oficiales subalternos (tenientes, alféreces, sargentos y cabos) 
de las compañías y escuadrones. Sin duda, fue una adecuación de la norma para mantener en servicio y con funcionalidad la Guardia Nacional en aquellos poblados.

Esta política de nombrar oficiales sin elecciones terminó siendo refrendada con las reformas militares de inicios de los años cuarenta, cuando se sancionó que la designación de los oficiales de las Guardias Nacionales se haría por medio de las ternas nombradas por las jefaturas políticas y refrendadas por la Secretaría de Guerra; de esta manera se eliminó el acto democrático. Las posibles razones de este cambio pueden radicar en las dificultades que la votación generaba, siendo más convenientes las ternas, cuyo nombramiento implicaba señalar las cualidades y méritos de los candidatos. Por ejemplo, en junio de 1843, el jefe político del cantón de Almaguer, Juan Antonio Morcillo, comunicó al gobernador el envío de las propuestas para oficiales de las compañías de Guardia Nacional Auxiliar de las cabeceras cantonales de Pancitará, El Trapiche y El Rosal. En el caso de la primera compañía, después de nombrar a los nominados, agregó: "Estos vecinos son residentes en este distrito; con notable honradez, de acreditado patriotismo e inmejoral [sic] y los dos primeros en particular han prestado voluntariamente sus servicios en defensa del gobierno". Es claro en la misiva que a pesar de proponer una terna, se destaca a ciertas personalidades de la lista, como se evidencia con más claridad respecto a Joaquín María Guzmán, propuesto como alférez abanderado, de quien Morcillo decía:

Este ciudadano es residente en este distrito parroquial, honrado, patriota, ha desempañado las funciones de juez de $1^{\underline{a}}$ instancia de este cantón el año de 1840, con alguna regularidad; ha prestado sus servicios en calidad de soldado de esta guardia nacional, en el año de 1841, al principio y después los volvió a prestar en servicio en calidad de alférez $1^{\circ}$ y por último ha servido de alcalde parroquial de este distrito por algún tiempo, hasta que por una enfermedad renunció (ACC. AM, 1842, Paq. 35, leg. 44).

En otro documento, de 1843, redactado por la jefatura y el Concejo municipal de Caloto, se muestra otro escenario para la designación de oficiales. En este caso se cumple con la norma, al presentar la terna, señalando enseguida las cualidades y virtudes de sus integrantes: 
Propuesta para Capitán de la $1^{\text {a }}$ compañía

- Andrés Saa, con las cualidades de patriotismo, entre ellas ser honrado, vecino y residencia de Quilichao, no tuvo comprometimiento alguno en los pasados trastornos políticos.

- Miguel Sarmiento cualidades de patriotismo, defendió al gobierno central en los pasados trastornos políticos y además estuvo en 1841 en el sitio de Popayán defendiendo la ciudad, en clase de soldado.

- Sebastián Bermúdez, cualidades de patriotismo; ha defendido siempre al gobierno y es vecino y residente en Quilichao (ACC. AM, 1843, Paq. 37, leg. 76).

Lo que expresó la nueva normatividad fue el reconocimiento del poder que tenían ciertos personajes locales para convocar a sus vecinos y organizar las Guardias Nacionales. Las bases de autoridad de estos personajes descansaban en sus redes de adscripción y fidelidades, a partir de la amistad, el patronazgo y el compadrazgo, construidos desde los tiempos de la independencia, lo que les permitía tener a disposición una hueste cuando la requiriese el Estado republicano. Si bien algunos eran propietarios de estancias agrícolas o "fincas", para la mayoría la tierra no era la fuente de su poder y prestigio, pues no disponían de una gran población trabajadora, sujeta a relaciones laborales que crearan ataduras. Su capacidad de reclutamiento, en cambio, pasaba por la legitimidad de la que estaban investidos frente a sus paisanos.

El Estado, en su esfuerzo de cristalizar las compañías de milicia, cooptó a los notables locales y de esta manera obtuvo la legitimidad de la que carecía en los poblados, por mediación de estos personajes, convirtiéndolos en los comandantes por antonomasia de los respectivos cuerpos armados de donde eran vecinos (Lynch, 1987, p. 101). Por ello, las administraciones nacionales de los años treinta y cuarenta tuvieron la precaución de atraerlos y mantenerlos a su disposición, como sus agentes directos en las localidades, por mediación de los gobernadores provinciales. Las administraciones de José Ignacio Márquez (1837-1841), Pedro Alcántara Herrán (18411845) y Tomás Cipriano de Mosquera (1845-1849) los vincularon a su agrupación política, por medio de ascensos en el escalafón militar, su inclusión en la nómina de militares, como pensionados o activos, y otorgándoles fuero en tiempos de paz. 
La importancia de estos hombres para el control territorial quedó expresada en una carta escrita en Bogotá por el entonces Secretario del Interior, Juan de Dios Aránzazu, el 25 de octubre de 1839, y enviada al General Pedro Alcántara Herrán, comandante encargado de las operaciones sobre Pasto, en donde había estallado una rebelión. En ella se le recordaba al General la importancia de ganarse en la región del Patía a sus líderes naturales:

Los Patianos, Sarria con su Indulto y Córdoba con la confianza que de él se ha hecho, quedarán hechos unos perros ministeriales. El cuidado de acabarlos, de echarlos a perder será de usted, estas son ganancias muy positivas en favor del orden y la estabilidad de las instituciones (AGN. ACH. FPAH. Rollo 5, caja 8, carpeta [carp.] 36, f. 4).

También su valía la expresó en su momento el Sargento mayor Bartolomé Castillo, comandante general de la Guardia Nacional Auxiliar de Popayán, quien, al enterarse del levantamiento de Pasto de junio de 1839, de inmediato llamó al servicio a estos jefes naturales, con la orden de organizar las Guardias de sus parroquias y ponerlas a disposición del gobierno. Esta era una forma de adelantarse a los agentes rebeldes para que no sumaran adhesiones a la insurrección, pues los vecinos en armas y contrarios al gobierno serían un serio problema para el orden (ACC. AM, 1839, Paq. 29, leg. 21; AGN. ACH. FPAH. Rollo 7, caja 12, carp. 53).

Pero esta acción no fue exclusiva de Popayán y sus distritos. A mediados de los años treinta, las autoridades de Palmira, perteneciente a la provincia del Cauca, se percataron de que la única manera de lograr una convocatoria exitosa a la Guardia Nacional era designando como oficiales a las personalidades influyentes de la región. De esta manera, el 23 de abril de 1834, la jefatura municipal presentó ternas de capitanes, tenientes, y alférez $1^{\circ}$ y $2^{\circ}$ (ver tabla 1), para los escuadrones que se debían organizar, con la característica principal de estar constituidas por hacendados y personas prestantes de la región. 


\section{Tabla 1}

\section{Ternas de oficiales del escuadrón de Guardia Nacional de}

Palmira (1835)

\begin{tabular}{l|l|l|l|l}
\hline Capitanes: & Teniente 1ำ & Tenientes 2o & Alférez 1o & Alférez 2o \\
Elías Soto & Lucas Valdivieso & Agustín Jaramillo & Ramón Zorrilla & Joaquín Herrera \\
Santiago Bejarano & Joaquín González & Simón Bejarano & Joaquín Gómez & Roto Bustamante \\
Gabriel Prado & Miguel Escobar & Ramón Barona & Juan Avenía & Roto Domínguez \\
Rafael Prado & Juan Vicente & Joaquín Soto & Francisco Saa & Rafael Soto \\
José María Patiño & Bejarano & Joaquín Cárdenas & Agustín Quintero & Santos Martínez \\
Pedro Quintero & Manuel Antonio & Francisco Delgado & Pedro Zorrilla & Domingo Martínez \\
Cayetano Escobar & Molina & Juan Cuevas & José Antonio & Cipriano Girón \\
José María & Francisco Sinis- & Francisco Zorrilla & Saavedra & Gabriel Baena \\
González & terra & Simón Saavedra & José María Vivas & Juan de Dios Olave \\
Luis Molina. & Ramón Sinisterra & José Tomás & Rafael González & \\
& Tomás Soto & Sánchez & Federico Valdés & \\
& & & Inocencio Silva & \\
& & Juan Antonio & \\
& & Saavedra & \\
\hline
\end{tabular}

Fuente: Carta de la jefatura municipal del cantón, Palmira, abril 23 de 1835 (ACC. AM, 1834, Paq. 24, leg. 25).

La lista de los oficiales propuestos en este caso tiene en común que la mayoría de los identificados documentalmente eran propietarios de haciendas o medianas estancias; letrados con aires de abogados, es decir, leguleyos; residentes en Palmira o en los sitios de la extensa zona rural que comprendía el cantón en mención. Todos con fuerte influencia en las comunidades rurales, por las múltiples relaciones constituidas entre los campesinos, otorgándoles preeminencia sobre los caseríos dispersos de la jurisdicción.

Los oficiales identificados en general aparecen como "ricos campesinos" en los informes elaborados por las autoridades cantonales en 1842, sobre las personas notables y prominentes de la región. Elías Soto o Fernández de Soto era propietario de una hacienda a una legua de distancia de Palmira y fue congresista conservador por la provincia del Cauca (1850); Santiago Bejarano, dueño en ese momento de la Hacienda La Quita, aparece en los años veinte frecuentemente en la lista de los contribuyentes al impuesto directo; Lucas Valdivieso era poseedor de la Hacienda La Granja y de potreros en La Herradura, Sumbaculo y Aguaclara, así como de derechos en el indiviso del Bolo; Cayetano Escobar era dueño del Bolo de los Escobares; era un hombre rico, pero apático, que buscaba excusarse 
de todo servicio a la República. Una hija suya se casó con Lucas Valdivieso y esta fue la tendencia de las demás, desposadas con ricos propietarios de Palmira y Buga. Miguel Escobar, también hacendado, era rematador del derecho de destilación y venta de aguardiente en Palmira, Candelaria y Florida, siendo su fiador José Joaquín Escobar Torres; similares características tenían Manuel María y Luis Molina, Francisco y Ramón Sinisterra, entre otros (ACC. AM, 1835, Paq. 25, leg. 29; 1846, Paq. 40, leg. 61; AGN. ACH. FPAH. Rollo 3, legajo 6, f. 1-75; Arboleda, 1962, p. 159; Arboleda, 1990, p. 134; Bastidas, 1989, pp. 57-58; Díaz, 1987, p. 21; Lobato, 1994, pp. 170-172; Zúñiga y Castro, 1989, pp. 28-54).

En otras localidades de la jurisdicción de Cali y Pasto, la designación de los cuadros de oficiales para las Guardias Nacionales tuvo la misma lógica, al recaer en las personas notables de las localidades: hombres con la capacidad de convocar, persuadir, organizar y disciplinar a los vecinos reticentes a formar parte de las milicias. El hecho podría parecer un fracaso de la norma, pero la práctica no fue exclusiva de la Nueva Granada; en los Estados Unidos, las milicias estatales fueron comandadas por los notables de los pueblos, a finales del siglo XVIII (Morgan, 2006, p. 181). La tendencia también se presentó a lo largo de Latinoamérica, donde las milicias fueron dirigidas por los poderosos locales (Buchbinder, 2005; Murilo de Carvalho, 1995, pp. 31-44).

Esta práctica contribuyó al espíritu de cuerpo, como lo señala Morgan (2006, p. 180) para los EE. UU., por la camaradería que se constituía entre oficiales y milicianos, ligando a los de arriba con los de abajo. En nuestro caso, existen referencias acerca de que los jefes y capitanes de las compañías de la Guardia Nacional se convirtieron en los representantes de sus huestes ante las autoridades civiles y militares, en lo concerniente al pago del prest, raciones, dotación (uniforme) y otros asuntos más.

La característica aludida nos indica que los cuerpos de Guardia Nacional fueron un espacio de camaradería, constituido sobre las redes y vínculos locales en torno a un sujeto de prestigio. Tal vez por esta razón Bartolomé Castillo, originario de Cuba, cuando fungió de Comandante general de la Guardia Nacional de Popayán en los 
años cuarenta, promovió la idea de formar compañías por parroquias y no uniendo a varias de ellas. El habanero era consciente de que la cohesión de la hueste se fundaba sobre las relaciones de vecindad existentes entre sus miembros y por la adscripción de los mismos a su comandante, gracias a la costumbre -de la cotidianidad aldeana- de la deferencia y obediencia a ciertos hombres, por la posición social que ocupaban en la parroquia. En la vida diaria estos comandantes eran funcionarios locales, mayordomos de fábrica, los principales en las procesiones de la Semana Santa, los que financiaban las fiestas, etc. En otras palabras, con los notables a la cabeza de la Guardia Nacional, se reproducían las jerarquías habituales; de ahí la poca conveniencia de elegir oficiales advenedizos, procedentes de otras aldeas, pues esto alteraría la estructura de mando cotidiana.

La práctica temprana de los funcionarios de Popayán de nombrar como comandantes a personas prominentes locales, que después se volvió la regla para el suroccidente por medio de las ternas, supuso el reconocimiento tácito de la existencia de hombres de prestigio social, legitimidad y autoridad suficientes para organizar y mantener las milicias en los distritos parroquiales. Sin ellos, el decreto quedaba en el papel, pues cualquier acto de constituir la Guardia por medio de la aplicación de la norma se estrellaba con la indiferencia de los vecinos y las resistencias comunales, que solo podían ser salvadas si el encargado era un personaje prominente en el entramado local. El Estado, carente de legitimidad, debió penetrar las territorialidades por medio de estos agentes, quienes fueron sus intermediarios.

Incluso el partido liberal, un año después de obtener el poder nacional en 1849 y cuando ya controlaba "las provincias del Cauca” (Pasto, Popayán, Cauca y Buenaventura), recurrió a la misma práctica de los gobiernos antecesores: nombrar como comandantes de las Guardias Nacionales a notables locales, eso sí, afiliados a las redes del liberalismo regional. De esta forma, en 1850 se designó como comandante del emblemático escuadrón de Húsares del Patía al teniente coronel Manuel María Vargas; en el Tambo, al capitán Francisco Solarte; en Timbío, a Julián Valverde y José Manuel Pérez; en Silvia, a Nicolás Hurtado; en La Horqueta-La Sierra, a Santiago Valencia y Juan Bautista Sandoval; y en Quilichao, a Manuel An- 
tonio Tello (ACC. AM, 1850, Paq. 48, leg. 64; 1850, Paq. 49, leg. 80, 81; 1851, Paq. 50, leg. 43, 50; 1851, Paq. 51, leg. 62, 63, 65, 67; 1851, Documentos de diversas comandancias militares; 1851, Documentos gobernación de la provincia de Popayán; 1851, Documentos gobernaciones de las provincias de Popayán, Cauca y Pasto).

Similar medida adoptó el gobernador de Buenaventura, al designar como comandantes y oficiales de las compañías de Guardia Nacional de su jurisdicción a Manuel José Núñez Conto, Cesáreo Sánchez y Pedro Constaín, hombres vinculados al partido y a las sociedades democráticas regionales, y, ante todo, sujetos de preeminencia social. El primero era médico, perteneciente a una de las familias más poderosas de la región; el segundo había sido estudiante del colegio de Santa Librada, miembro de la municipalidad del puerto de Buenaventura y activo promotor de las sociedades democráticas; junto con Pedro Constaín, natural Popayán, pero radicado a mediados de los cuarenta en Cali, dedicado al comercio y cercano al círculo del gobernador Mercado (Arboleda, 1966, pp. 12, 122, 310, 401-402; Mercado, 1996, pp. 63-75).

En resumen, los designados para comandar las milicias fueron los jefes naturales o los magnates locales, con amplias redes de poder, prestigio, recursos económicos y capitales simbólicos (saber leer y escribir, por ejemplo); que los dotaron de la influencia y autoridad necesarias en sus entramados sociales para persuadir a sus vecinos de formar parte de las Guardias Nacionales de sus localidades. Sin ellos no se puede entender cómo, en tiempos de convulsiones políticas, los ejércitos gubernamentales se elevaban exponencialmente y marchaban a cientos de kilómetros de sus hogares para hacer frente a las fuerzas opuestas al gobierno legítimo. Pero su presencia también explica cómo los rebeldes formaban rápidamente cuerpos armados, con los cuales cuestionaban la legitimidad del Estado.

En todo caso, sin estas unidades armadas, nunca podremos entender el desenvolvimiento de las guerras civiles en Colombia y en Latinoamérica, ya que su institucionalización llevó a hacer más volátil el orden público, frente a un Estado que de alguna manera promovió y legitimó la dispersión de las armas en estas compañías. De esta manera, el Estado le otorgó más sustancia, por así decirlo, a 
la ciudadanía armada, que finalmente vino a ser cuestionada a partir de las políticas de profesionalización del ejército regular, asociadas a misiones militares extranjeras a finales del siglo XIX (Loveman, 1999, pp. 63-99; Sabato, 2018, pp. 90-118; Velásquez, 2018, pp. 495-537).

\section{Conclusión}

Los procesos de construcción estatal son multidireccionales, como lo evidencia ya una amplia bibliografía sobre el tema, que señala la importancia de diversos factores en el proceso de institucionalizar el Estado. Así, el presente artículo muestra cómo el proceso de institucionalizar compromete dos actos: el instituir y el instituyente. El primer acto se expresa por medio de una norma, ley o decreto, que busca que el ideal plasmado en el papel se ponga en práctica. El segundo acto es el de hacer realidad la norma, es decir, es el proceso de convertir la letra en acción, en práctica; pero en él múltiples variables entran en juego: las condiciones de la infraestructura del Estado, las resistencias de los grupos humanos, la interpretación y la adaptación de la norma, entre otras. En ese camino, el ideal legislativo no siempre es el resultado final, pero en todo caso el producto es una institucionalidad en cuya conformación la sociedad no ha estado ausente, inerme o pasiva; por el contrario, ha participado activamente del proceso.

Por lo señalado, toda intención de fundar un orden por parte del Estado termina, en parte, con la sociedad fundando el Estado. Esta paradoja nos sugiere que los procesos de construcción estatal no son nunca unidimensionales; el ejemplo de la conformación de las Guardias Nacionales en las provincias del Cauca (Pasto, Popayán, Cauca y Buenaventura), en la primera mitad del siglo XIX, es un ejemplo de lo dicho. La legislación de los años veinte y treinta contempló todo lo necesario para la organización, disciplina y manejo de las Guardias Nacionales; no obstante, el proceso fue siempre tortuoso, pues se enfrentó a las resistencias comunales, a la ausencia de suficientes equipos militares y demás abastecimientos (uniformes, por ejemplo), y a la apatía de los residentes parroquiales para formar compañías de milicia. El Estado, representado en los 
funcionarios provinciales y cantonales, debió hacer adecuaciones o adaptaciones a la norma para volver operativas las Guardias.

En la marcha, frente a la necesidad de constituir milicias armadas disciplinadas y con espíritu de cuerpo, varios componentes de la norma se tuvieron que abandonar y, con ello, hubo que tolerar ciertas prácticas, como la del padrino de la bandera, en la jura del símbolo nacional. Pero más significativo fue el papel central que desempeñaron los magnates o notables locales, quienes en la práctica fueron las personalidades vertebradoras de las Guardias Nacionales. Gracias a ellos, se logró institucionalizar las compañías y escuadrones de Guardia Nacional, pero por una mediación, que en la práctica significó que el Estado le entregaba el control de estas unidades a unos hombres a quienes, para mantenerlos bajo su dosel, fue necesario ofrecerles ciertas garantías y prebendas, terminando por adscribirlos a las agrupaciones políticas.

Pero lo señalado no significó que las Guardias Nacionales terminaran sujetas a los intereses faccionales de los grupos de poder rivales. Sus derroteros muestran que para el Estado fueron efectivas compañías de combate en tiempos de guerras civiles y de gendarmería, en tiempos de paz. Además, desempeñaron diversas tareas, como la de escolta de correos, o la remisión de reos o pliegos judiciales, contribuyendo al despliegue de la estatalidad en los sitios más recónditos de la geografía caucana de aquel entonces $\mathbf{I}$

\section{Referencias}

Arboleda, G. (1962). Diccionario biográfico y Genealógico del Antiguo Departamento del Cauca. Librería Horizontes.

Arboleda, G. (1990). Historia contemporánea de Colombia (Tomo v). Banco Central Hipotecario.

Aurell, J. (2017). La escritura de la memoria. De los positivistas a los posmodernismos. Universitat De Valéncia.

Bastidas, H. (1989). Hacendados y plebeyos en la Palmira republicana, 18241854 [Tesis de Licenciatura en Historia]. Universidad del Valle. 
Bosch, M. J. (1996). Reseña de los principales acontecimientos políticos de la ciudad de Cali, desde el año de 1848 hasta el de 1855 inclusive. Centro de Estudios Históricos y Sociales / Imprenta Departamental.

Buchbinder, P. (2005). Estados, caudillos y organización miliciana en la provincia de Corrientes en el siglo XIX: el caso de Nicanor Cáceres. Revista de Historia de América, (36), 36-64, https://bit.ly/2QGDO1P.

Díaz, Z. (1987). La Villa de Palmira en el periodo de la independencia, 17801830. Cámara de Comercio de Palmira.

Galante, M. (2006). De revoluciones, repúblicas y naciones. Miradas sobre América Latina desde la Nueva Historia Política. Mexican Studies/Estudios Mexicanos, 22(2), 417-448. https://doi.org/10.1525/ msem.2006.22.2.417.

Harari, E. (2013). La organización miliciana en Buenos Aires (1810-1820): creación, reclutamiento y elección de oficiales. Temas Americanistas, (31), 98-123. https://bit.ly/31Z507w.

Hébrard, V. (2002). ¿Patricio o soldado: qué "uniforme" para el ciudadano? El hombre en armas y la construcción de la nación (Venezuela en la $1^{\text {a }}$ mitad del siglo XIX). Revista de Indias, 62(225), 429-462. https://bit. ly/3crcZrO.

Irurozqui, M. (2011). La Justicia del pueblo. Ciudadanía armada y movilización social. En M. Irurozqui y M. Galante (Eds.), Sangre de ley. Justicia y violencia en la institucionalización del Estado en América Latina (pp. 235-276). Polifemo.

Irurozqui, M. (2018). Ciudadanos armados de ley. A propósito de la violencia en Bolivia, 1839-1875. IFEA, Plural Ediciones.

Joseph, G. y Nuguet, D. (Comp.) (2002). Aspectos cotidianos de la formación del Estado. La revolución y la negociación del mando en el México moderno. Era.

Lobato, L. (1994). Caudillos y Nación. Sociabilidades Políticas en el Cauca, 1830-1860 [Tesis Maestría en Historia Andina]. Universidad del Valle.

Loveman, B. (1999). For la Patria. Politics and the Armed Forces in Latin American. Scholary Resources Inc. 
Lynch, J. (1987). Hispanoamérica, 1750-1850. Ensayos sobre sobre Sociedad y Estado. Universidad Nacional de Colombia.

Lynn, J. A. (1996). The evolution of army style in the modern west, 8002000. The International History Review, 18(3), 505-545.

Macías, F. (2001). Guardia Nacional, ciudadanía y poder en Tucumán, Argentina (1850-1880). Revista Complutense de Historia, (27), 131-161. https://bit.ly/2NZgIm8.

Macías, F. (2016). El deber de enrolarse y el derecho a votar. Reflexiones en torno a la ciudadanía armada y el sufragio en argentina, 18631877. Revista de Indias, 76(266), 233-258. https://ri.conicet.gov.ar/ handle/11336/39811.

McNeill, W. (1989). La Búsqueda del poder: Tecnología, fuerzas armadas y sociedad, desde el 1.000 d. C. Siglo XXI .

Mercado, R. (1996). Memorias sobre los acontecimientos del sur de la Nueva Granada durante la administración del 7 de marzo de 1849. Imprenta Departamental del Valle, Centro de Estudios Históricos y Sociales.

Mintz, S. \& Wolf, E. (1978). An analysis of ritual co-parenthood (compadrazgo). In S. W. Schmidt et al. (Eds.), Friends, Followers and Factions. A Reader in Political Clientelism. (pp. 1-15). University California Press,

Morgan, E. (2006). La invención del pueblo: El surgimiento de la soberanía popular en Inglaterra y Estados Unidos. Siglo XXI.

Murilo de Carvalho, J. (1995). Desenvolvimiento de la ciudadanía en Brasil. Fondo de Cultura Económica.

Nutini, H. y Bell, B. (1989). Parentesco ritual. Estructura y evolución histórica del sistema de compadrazgo en la Tlaxcala rural. Fondo de Cultura Económica.

Prado, L. (2012). El jefe natural: poder y autoridad en el valle del Patía, 1810-1850. Historia y Sociedad, (23), 243-265. https://bit.ly/3rzA9jc.

Prado, L. (2013). Redes, movilización y bases de autoridad en el valle del Patía, 1820-1851. Historia Caribe, 8(22), 75-103. https://bit.ly/2QHS8Hr. 
Sabato, H. (2018). Republics of the new world. The revolutionary political experiment in $19^{\text {th }}$-century Latin American. Pricenton University Press.

Sala de Negocios Generales del Consejo de Estado (Comp.) (1924). Codificación Nacional de todas las leyes de Colombia desde el año de 1821, hecha conforme a la ley 13 de 1912 (Tomo 2, 1825 y 1826). Imprenta Nacional.

Sala de Negocios Generales del Consejo de Estado (Comp.) (1925). Codificación Nacional de todas las leyes de Colombia desde el año de 1821, hecha conforme a la ley 13 de 1912 (Tomo 3, 1827 y 1828). Imprenta Nacional.

Sala de Negocios Generales del Consejo de Estado (Comp.) (1926). Codificación Nacional de todas las leyes de Colombia desde el año de 1821, hecha conforme a la ley 13 de 1912 (Tomo 8, 1838-1840). Imprenta Nacional.

Sala de Negocios Generales del Consejo de Estado (Comp.) (1927). Codificación Nacional de todas las leyes de Colombia desde el año de 1821, hecha conforme a la ley 13 de 1912 (Tomo 9, 1841-1842). Imprenta Nacional.

Sala de Negocios Generales del Consejo de Estado (Comp.) (1928). Codificación Nacional de todas las leyes de Colombia desde el año de 1821, hecha conforme a la ley 13 de 1912 (Tomo 13, 1848-1849). Imprenta Nacional.

Sandoval, P. (2010). Repensando la subalternidad. Miradas críticas desdel sobre América Latina. Instituto de Estudios Peruanos, Envión Editores.

Sobrevilla, N. (2019). Los inicios de la república peruana. Viendo más allá de la "Cueva de bandoleros". Fondo Editorial Universidad Católica del Perú.

Thomson, G. (1990). Bulwarks of Patriotic Liberalism: The National Guard, Philharmonic Corps and Patriotic Juntas in Mexico, 184788. Journal of Latin American Studies, 22(1), 31-68. http://dx.doi. org/10.1017/S0022216X00015108.

Velásquez, D. (2018). Una mirada a largo plazo: armas, política y guerras en el siglo xix. En C. McEvoy y A. Rabinovich (Eds.), Tiempo de guerra. Estado, Nación y conflicto armado en el Perú, siglo XVII-XIX (pp. 495-537). 
Instituto de Estudios Peruanos.

Zúñiga, M. y Castro, J. (1989). El proceso de evolución de grandes globos indivisos de tierras en centros urbanos de los municipios de Candelaria y Florida en el siglo XIx [Tesis Licenciatura en Historia]. Universidad del Valle.

\section{Archivos}

Archivo Central del Cauca. Archivo Muerto (ACC. AM). 1833, Paquete 23, legajo 15.

Archivo Central del Cauca. Archivo Muerto (ACC. AM). 1834, Paquete 24, legajo 25.

Archivo Central del Cauca. Archivo Muerto (ACC. AM). 1835, Paquete 25, legajos 24, 29.

Archivo Central del Cauca. Archivo Muerto (ACC. AM). 1837, Paquete 37, legajo 72.

Archivo Central del Cauca. Archivo Muerto (ACC. AM). 1839, Paquete 29, legajos 21, 25, 27.

Archivo Central del Cauca. Archivo Muerto (ACC. AM). 1840, Paquete 31, legajo 46.

Archivo Central del Cauca. Archivo Muerto (ACC. AM). 1842, Paquete 35, legajos 42, 44 .

Archivo Central del Cauca. Archivo Muerto (ACC. AM). 1843, Paquete 36 , legajos $27,47$.

Archivo Central del Cauca. Archivo Muerto (ACC. AM). 1843, Paquete 37, legajos 70, 76.

Archivo Central del Cauca. Archivo Muerto (ACC. AM). 1846, Paquete 40, legajo 61.

Archivo Central del Cauca. Archivo Muerto (ACC. AM). 1850, Paquete 48, legajo 64.

Archivo Central del Cauca. Archivo Muerto (ACC. AM). 1850, Paquete 49, legajos 76, 80, 81. 
Archivo Central del Cauca. Archivo Muerto (ACC. AM). 1851, Paquete 50, legajos 43, 50, 51.

Archivo Central del Cauca. Archivo Muerto (ACC. AM). 1851, Paquete 51, legajos 48, 62, 63, 65, 67 .

Archivo Central del Cauca. Archivo Muerto (ACC. AM). 1851, Documentos de diversas comandancias militares.

Archivo Central del Cauca. Archivo Muerto (ACC. AM). 1851, Documentos gobernación de la provincia de Popayán.

Archivo Central del Cauca. Archivo Muerto. (ACC. AM). 1851, Documentos gobernaciones de las provincias de Popayán, Cauca y Pasto.

Archivo Central del Cauca. Archivo Muerto (ACC. AM). 1852, Paquete 53, legajo 77.

Archivo Central del Cauca. Fondo Arboleda (ACC. FA). Signatura 336.

Archivo General de la Nación. Academia Colombiana de Historia. Fondo Pedro Alcántara Herrán (AGN. ACH. FPAH). Rollo 3, legajo 6.

Archivo General de la Nación. Academia Colombiana de Historia. Fondo Pedro Alcántara Herrán (AGN. ACH. FPAH). Rollo 5, caja 8, carpeta 36.

Archivo General de la Nación. Academia Colombiana de Historia. Fondo Pedro Alcántara Herrán (AGN. ACH. FPAH). Rollo 6, legajo 10.

Archivo General de la Nación. Academia Colombiana de Historia. Fondo Pedro Alcántara Herrán (AGN, ACH. FPAH). Rollo 7, caja 12, carpeta 53, sin foliación.

Archivo General de la Nación. Secretaría de Guerra y Marina (AGN. SGM). Tomo 160.

\section{Periódicos}

Gaceta de la Nueva Granada, Bogotá 30 de mayo de 1832, No. 34. 